\title{
ROBUSTNESS OF CONTACTLESS OPTICAL METHOD USED FOR MEASURING CONTACT WIRE POSITION IN CHANGEABLE LIGHTING CONDITIONS
}

\author{
Jacek Skibicki
}

Original scientific paper

The article presents verification of robustness of contactless method based on 2D image camera, which is used to measure catenary contact wire position in changeable ambient lighting conditions. Robustness in changeable lighting conditions is ensured through the combination of advanced image processing for background information removal and the algorithm of error correction. This algorithm detects incorrect images and substitutes information from these images with proper measurement data obtained from correct images which precede and follow the incorrect one. The paper presents and discusses the processing algorithms used, as well as shows examples of measurement results obtained on a full scale laboratory stand.

Keywords: contact line; diagnostic systems; electric traction; measurement systems

\section{Robustnost bezkontaktne optičke metode korištene za mjerenje položaja žice spoja u promjenjivim uvjetima osvjetljenja}

Izvorni znanstveni članak

U članku je prikazana provjera robustnosti bezkontktne metode utemeljene na 2D fotoaparatu, koja se koristi za mjerenje položaja žice spoja u promjenjivim uvjetima osvjetljenja okoline. Robustnost u promjenjivim uvjetima osvjetljenja osigurana je kombinacijom napredne obrade slike za uklanjanje pozadinskih informacija i algoritma ispravljanja pogrešaka. Ovaj algoritam otkriva netočne slike i nadomješta informacije s ovih slika s odgovarajućim mjernim podacima dobivenim od ispravnih slika koje prethode i slijede pogrešnu. Rad prikazuje i raspravlja o korištenim algoritmima za obradu, te pokazuje primjere rezultata mjerenja dobivenih na laboratorijskom mjernom pultu.

Ključne riječi: dijagnostički sustavi; električna vuča; kontakt linija; mjerni sustavi

\section{Introduction}

Increase in the power consumed by electric traction vehicles and increase of their speed result in higher technical requirements for the contact line parameters, for example those connected with delivering a sufficient level of electric power to the vehicle, and those connected with geometrical parameters of the contact line itself. Providing proper geometrical parameters is closely connected with technical diagnostics of the contact line.

Technical diagnostics of contact line involves a wide range of activities, from measuring the geometry of contact line in static conditions (without the influence of a current collector) and in dynamic conditions (where the influence of a current collector is taken into consideration) to measuring the degree of contact wire wear $[1,2]$. Methods for measuring the position of contact wires include contact and contactless ones [1-3]. The contact methods usually involve the use of specially constructed current collectors which allow for measuring the geometry of contact line and detecting some of the irregularities in its construction, e.g. so-called hard points [3-6]. Contactless methods, which may be used only for static measurements, usually require the use of laser scanners or vision cameras [2, 7-10]. Sometimes a combination of measurement current collectors and cameras is employed [4, 7, 11]. The measurement of contact wire wear is performed, as a rule, with the use of laser scanners [4-7, 12-14].

The measurement method described in the article belongs to contactless methods using a $2 \mathrm{D}$ vision camera. The subject of the article is to verify the robustness of the method in changeable conditions of ambient lighting. Robustness in changeable conditions of ambient lighting is based on a combination of the elaborated advanced digital image processing algorithms - one used to remove background information from images and the other used to detect incorrect images. The principles of measurement method functioning have been defined. The way in which the algorithm for image analysis and error correction works has been described. Sample measurement results obtained at a stationary laboratory stand have been presented.

\section{Measurement method-principle of operation}

A 2D vision camera and a special slotted light source called "virtual current collector" are used to locate the catenary contact wire position. The measurement system produces images which contain visible points of light reflected from contact wires. This information, after being processed by removing the image background is converted into the measurement result (the values of height and stagger). The measurement principle is shown in Fig. 1 [15].

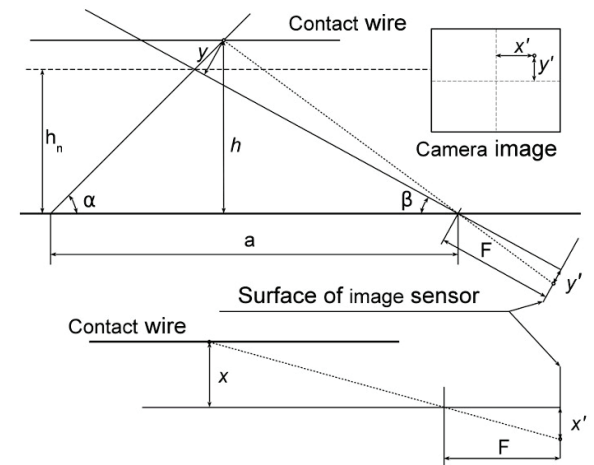

Figure 1 Principle of measurement method, where: $\alpha$-inclination angle of light source; $\beta$ - inclination angle of measurement camera; a distance between light source and camera focus lens; F - camera lens focal length; $x^{\prime}, y^{\prime}$ - coordinates of the light spot on the camera sensor to the centre of the image, corresponding to the position of light point with

coordinates $x, y ; h_{\mathrm{n}}$ - nominal suspension height of contact wire in relation to basic height (level of the measuring car roof); $h$-real (measured) suspension height of contact wire (in relation to basic height) 
The camera should be positioned in such a way that the light spot reflected from the contact wire, when being in the neutral position (at a nominal suspension height in Poland 5,6 m) and symmetrical position in relation to the track axis, is in the centre of the measurement image. In this situation the suspension height of contact wire and stagger are as follows [15]:

$$
\begin{gathered}
h=\frac{a \cdot \tan \alpha}{1+\frac{\tan \alpha \cdot\left(1-\frac{y^{\prime}}{F} \cdot \tan \beta\right)}{\tan \beta+\frac{y^{\prime}}{F}},} \\
x=\frac{\frac{x^{\prime}}{F} \cdot a \cdot \tan \alpha}{\tan \alpha+\left(\frac{\tan \beta+\frac{y^{\prime}}{F}}{1-\frac{y^{\prime}}{F} \cdot \tan \beta}\right)} .
\end{gathered}
$$

\section{Measurement processing}

The image captured by the camera is a colour image which contains both the proper information i.e. the light spot or spots reflected from the contact wires, as well as a lot of unwanted information, which should be removed during the analogous filtration and digital image processing. The image processing algorithm is therefore required to process the source image into a final image, from which all the unnecessary information has been deleted. The final image should contain only a spot or spots which are the reflection of the light beam from catenary contact wires. The next processing step is to determine the measurement result using Eq. (1) and (2). These results are the values of stagger and suspension height of the contact wire or wires. Afterwards, some error correction is necessary to remove the incorrect results which arise from incorrectly processed images. The aim of the image processing algorithm is to obtain measurement results. The entire measurement process has been shown in the block diagram presented in Fig. 2 .

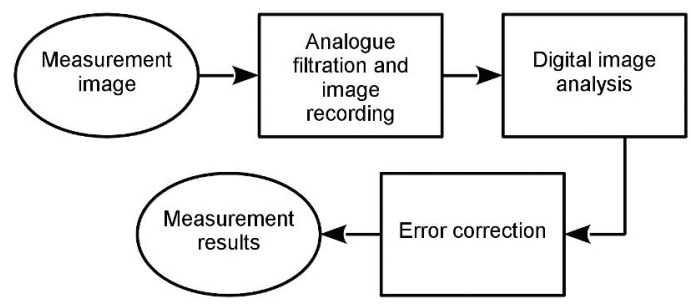

Figure 2 Block diagram of measurement process

\subsection{Analogous optical filtration}

The first phase of image processing is performed in the analogue way by using optical filtration. For this purpose, the band-pass filter type BP-640-100 by Schneider Kreuznach has been used. Its frequency characteristic is matched to the emission band of the red LEDs light source [16]. The characteristics of the optical filter and the diode are shown in Fig. 3. a)

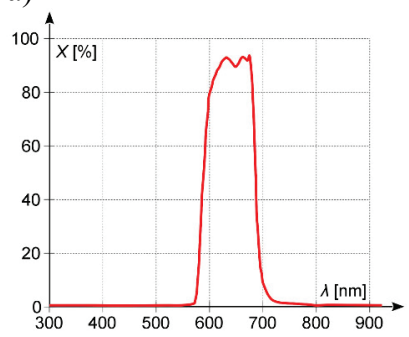

b)

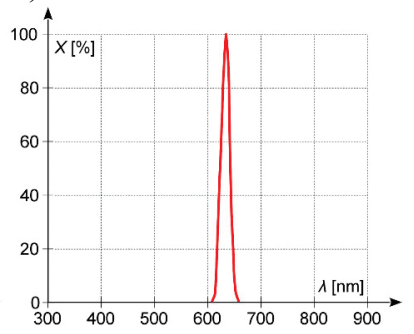

Figure 3 Frequency characteristics of optical filter and LED diode, where: a) band-pass filter characteristic; b) emission characteristic of the LED diode

Analogous filtration makes it possible to darken the background image and bring into prominence the points of light reflected from the contact wires. Thanks to that the next phase of processing i.e. "Digital image analysis" is easier and less complex.

\subsection{Digital image analysis}

The registered image (after optical filtration) is then changed by computer processing in order to eliminate all the unwanted information [17]. The image processing algorithm is shown in Fig. 4.

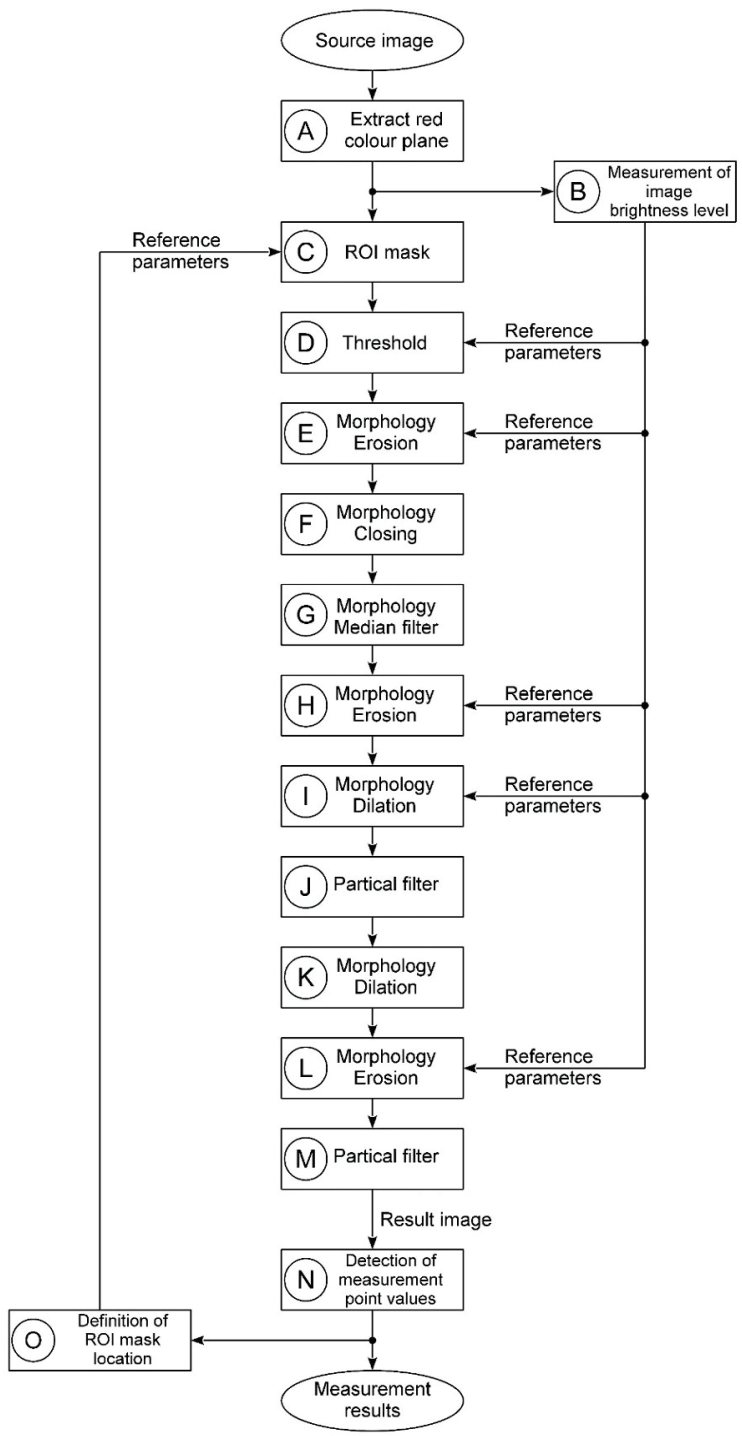

Figure 4 Algorithm of image analysis - description in text 
At the beginning only one colour plane (A) is extracted from the source image, which contains the RGB information. In this case, it means extraction of the $\mathrm{R}$ plane (red colour). Then the value of average image brightness is measured (B). Depending on the value of this parameter, the parameters of other image conversion phases are changed. Simultaneously with measurement of the image brightness the ROI (region of interest) mask is placed onto the image (C). This operation makes it possible to focus the analysis on the selected area of the frame, which should contain the light spot reflected from the contact wires. The ROI mask has the shape of a narrow rectangle, whose width is that of a picture frame. Its location depends on the place where the light spots, reflected from the contact wire, can be found on the previous frame $(\mathrm{O})$. This is acceptable because, in practice, suspension height of the contact wire cannot change rapidly. In the case of the first frame, or in the situation where the image processing algorithm has failed on the previous frame (there was no measurement result obtained), the entire surface of the image is taken into account as the region of interest.

The next step of image analysis is to perform the colour thresholding (D). This is the simplest method of segmentation, which allows for assignation of extreme values of brightness, i.e. 0 or 255 to all the pixels whose input brightness is above or below the established threshold levels. Because the brightness level of an input image can be changed within wide limits, the appropriate values of thresholds are selected based on measurement of this level. The result of this operation is a binary image.

The next processing operation is a morphological transformation sequence: erosion, closing, dilation and the median filter (some of these operations are performed twice) (E-I). They are used to clean the image of the interference of digital noise and allow for separation of the light spots which are looking for, in the situation where they are integrated with the image background. Some parameters of these transformations depend on the previously determined average brightness of the source image. This allows for adjustment of the required level of processing to the parameters of the input image.

Table 1 Structure of text file with measurement results

\begin{tabular}{|c|c|c|c|c|}
\hline Time $t$ & $\begin{array}{c}\text { Stagger } \\
\text { of the } \\
\text { first wire } \\
x_{1}\end{array}$ & $\begin{array}{c}\text { Stagger } \\
\text { of the } \\
\text { second } \\
\text { wire } x_{2}\end{array}$ & $\begin{array}{c}\text { Suspension } \\
\text { height of } \\
\text { the first } \\
\text { wire } h_{1}\end{array}$ & $\begin{array}{c}\text { Suspension } \\
\text { height of } \\
\text { the second } \\
\text { wire } h_{2}\end{array}$ \\
\hline$t_{1}$ & $x_{11}$ & $x_{21}$ & $h_{11}$ & $h_{21}$ \\
\hline$t_{2}$ & $x_{12}$ & $x_{22}$ & $h_{12}$ & $h_{22}$ \\
\hline$t_{3}$ & $x_{13}$ & $x_{23}$ & $h_{13}$ & $h_{23}$ \\
\hline$t_{4}$ & $x_{14}$ & $x_{24}$ & $h_{14}$ & $h_{24}$ \\
\hline$\vdots$ & $\vdots$ & $\vdots$ & $\vdots$ & $\vdots$ \\
\hline$t_{\mathrm{n}-3}$ & $x_{1 \mathrm{n}-3}$ & $x_{2 \mathrm{n}-3}$ & $h_{1 \mathrm{n}-3}$ & $h_{2 \mathrm{n}-3}$ \\
\hline$t_{\mathrm{n}-2}$ & $x_{1 \mathrm{n}-2}$ & $x_{2 \mathrm{n}-2}$ & $h_{1 \mathrm{n}-2}$ & $h_{2 \mathrm{n}-2}$ \\
\hline$t_{\mathrm{n}-1}$ & $x_{1 \mathrm{n}-1}$ & $x_{2 \mathrm{n}-1}$ & $h_{1 \mathrm{n}-1}$ & $h_{2 \mathrm{n}-1}$ \\
\hline$t_{\mathrm{n}}$ & $x_{1 \mathrm{n}}$ & $x_{2 \mathrm{n}}$ & $h_{1 \mathrm{n}}$ & $h_{2 \mathrm{n}}$ \\
\hline$t_{\mathrm{n}+1}$ & $x_{1 \mathrm{n}+1}$ & $x_{2 \mathrm{n}+1}$ & $h_{1 \mathrm{n}+1}$ & $h_{2 \mathrm{n}+1}$ \\
\hline$t_{\mathrm{n}+2}$ & $x_{1 \mathrm{n}+2}$ & $x_{2 \mathrm{n}+2}$ & $h_{1 \mathrm{n}+2}$ & $h_{2 \mathrm{n}+2}$ \\
\hline$t_{\mathrm{n}+3}$ & $x_{1 \mathrm{n}+3}$ & $x_{2 \mathrm{n}+3}$ & $h_{1 \mathrm{n}+3}$ & $h_{2 \mathrm{n}+3}$ \\
\hline$\vdots$ & $\vdots$ & $\vdots$ & $\vdots$ & $\vdots$ \\
\hline & & & & \\
\hline
\end{tabular}

In the next part of the processing, by using a partial filter, the objects which are too large or too small are removed from the image. Such objects may not constitute the reflection of light from the contact wire. This process is carried out in two stages, which are separated by morphological transformation, dilation and erosion performed yet again $(\mathrm{J}-\mathrm{M})$.

After this process, the result image should contain only a light spot or spots which are the reflection of light from the contact wires. Then the position of central pixels of these spots is detected $(\mathrm{N})$ and, on the basis of this information, in accordance with the dependencies (1) and (2), the measurement results, i.e. the suspension height of the contact wire and its stagger are obtained. The measurement results are saved as a text file in the order shown in Tab. 1.

\subsection{Error correction}

Despite using advanced processing of source image there is always a possibility that, for various reasons, a correct measuring result from the image may not be obtained. We can distinguish five types of wrong result images:

- $\quad$ incorrect image; completely black, without any light spots (type I);

- partially correct image; contains only one light spot instead of two (type II);

- partially correct image; contains two light spots, but only one of them is the reflection from the contact wire (type III);

- partially correct image; contains two light spots which are the reflection from the contact wire, and other spots, which are not the measurement result (type IV);

- incorrect image; contains light spots, none of which is the reflection from the contact wire (type V).

Erroneous results are corrected by analysing a text file which is the result of image processing algorithm. During this analysis it should be evaluated which measurement results are correct and which are incorrect. Defining incorrect results depends on the type of invalid frame from which they originate. In the case when the resulting image contains light spots other than the reflection from the contact wire (type III, IV and V), the obtained measurement results are significantly different from those originating from proper frames. It can therefore be assumed that the result which differs significantly from the results in its immediate neighbourhood, i.e. from the preceding and subsequent frames is wrong and needs to be corrected. Detection of incorrect images which do not contain any light spots, or contain only one is a bit simpler (type I and II). With this type of error calculation algorithm generates an incorrect result with a specific characteristic value $\left(h_{b}\right)$. This value depends on geometrical dimensions of the measuring system and other parameters which are constant for a given measurement stand. In this case this value will be constant and unchangeable. Consequently, if the measurement result takes this value, it can be assumed that such a result is incorrect.

The method of error correction depends on the sequence of correct and incorrect frames. Correction of a single incorrect frame, i.e. where the preceding and 
subsequent frames are correct, is performed in accordance with Eq. (3). This equation is valid for the stagger of the first contact wire $\left(x_{1}\right)$. Analogous equations are used for correction of other measurement values: the stagger of the second contact wire $\left(x_{2}\right)$, the suspension height of the first contact wire $\left(h_{1}\right)$ and the suspension height of the second contact wire $\left(h_{2}\right)$.

$x_{1 n}{ }^{\prime}=\left\{\begin{array}{cc}x_{1 n} & \left(\begin{array}{c}\text { for lack of } \\ \text { error images }\end{array}\right) \\ \frac{x_{1 n-1}+x_{1 n+1}}{2} & \left.\begin{array}{c}\text { for detection of } \\ \text { single error image }\end{array}\right)\end{array}\right.$

Detection of frame type (error or correct) is carried out by logical analysis of the results obtained in tabular form (see Tab. 1). The logical condition for detection of correct frames is presented in Eq. (4), and for detection of single error frame in Eq. (5).

$$
\begin{gathered}
\left(\begin{array}{c}
\left|x_{1 n}-x_{1 n-1}\right|<0,02 \vee\left|x_{1 n}-x_{1 n+1}\right|<0,02 \vee \\
\left|x_{1 n}-x_{2 n-1}\right|<0,02 \vee\left|x_{1 n}-x_{2 n+1}\right|<0,02 \vee \\
h_{1 n-1}=h_{1 n+1}=h_{b} \vee h_{2 n-1}=h_{2 n+1}=h_{b}
\end{array}\right) \\
\left(\begin{array}{c}
\left|x_{1 n}-x_{1 n-1}\right|>0,02 \wedge\left|x_{1 n}-x_{1 n+1}\right|>0,02 \wedge \\
\left|x_{1 n}-x_{2 n-1}\right|>0,02 \wedge\left|x_{1 n}-x_{2 n+1}\right|>0,02 \wedge \\
\left(h_{1 n-1} \neq h_{b} \vee h_{1 n+1} \neq h_{b}\right) \wedge\left(h_{2 n-1} \neq h_{b} \vee h_{2 n+1} \neq h_{b}\right)
\end{array}\right)
\end{gathered}
$$

Dependence (3) allows for correction of a single incorrect frame for all types of wrong images where the wrong image appears once. For example, for the sequence: Good $\rightarrow$ Good $\rightarrow$ Bad $\rightarrow$ Good $\rightarrow$ Good. If the incorrect and correct picture frames appear alternately, i.e. in the sequence: $\mathrm{G} \rightarrow \mathrm{B} \rightarrow \mathrm{G} \rightarrow \mathrm{B} \rightarrow \mathrm{G}$, correction will be possible, but only for the first and second type of wrong measurement images. The threshold value 0,02 depends on the assumed maximum allowable changes in the value of contact wire position which may occur for two consecutive measurement images. This value was chosen empirically by trial-and-error method. The same method was employed to select the thresholds appearing in Eq. (7-10) and (12-17).

Using Eq. (6) it is possible to perform correction in a situation where two frames are incorrect, and at least one preceding and one subsequent frame are correct. As before, Eq. (6) relates to the stagger of the first contact wire $\left(x_{1}\right)$. Equations for other values are similar.

$$
x_{1 n}{ }^{\prime}=\left\{\begin{array}{cc}
x_{1 n} & \left(\begin{array}{c}
\text { for lack of } \\
\text { error images }
\end{array}\right) \\
\frac{x_{1 n-2}+x_{1 n+2}}{2} & \left(\begin{array}{c}
\text { for detection of two } \\
\text { error images; sequence: } \\
\mathrm{G} \rightarrow \mathrm{G} \rightarrow \mathrm{B} \rightarrow \mathrm{B} \rightarrow \mathrm{G} \rightarrow \mathrm{G}
\end{array}\right) \\
x_{1 n-1}+0,33 \cdot\left(x_{1 n+2}-x_{1 n-1}\right) & \left(\begin{array}{c}
\text { for detection of first } \\
\text { error image; sequence: } \\
\mathrm{G} \rightarrow B \rightarrow \mathrm{B} \rightarrow \mathrm{G}
\end{array}\right) \\
x_{1 n-2}+0,67 \cdot\left(x_{1 n+1}-x_{1 n-2}\right) & \left(\begin{array}{c}
\text { for detection of second } \\
\text { error image; sequence: } \\
\mathrm{G} \rightarrow \mathrm{B} \rightarrow B \rightarrow \mathrm{G}
\end{array}\right)
\end{array}\right.
$$

The logical condition for detection of correct frames is presented in Eq. (7), and for detection of error frames, respectively for each type of sequences, in Eq. (8-10).

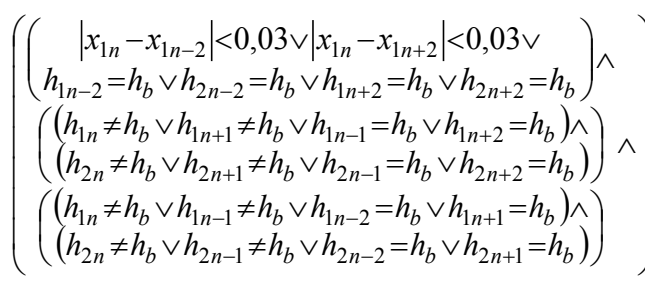

$$
\begin{aligned}
& \left(\begin{array}{c}
\left|x_{1 n}-x_{1 n-2}\right|>0,03 \wedge\left|x_{1 n}-x_{1 n+2}\right|>0,03 \wedge \\
h_{1 n-2} \neq h_{b} \wedge h_{1 n+2} \neq h_{b} \wedge h_{2 n-2} \neq h_{b} \wedge h_{2 n+2} \neq h_{b}
\end{array}\right)
\end{aligned}
$$

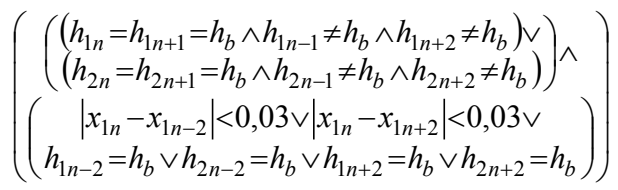

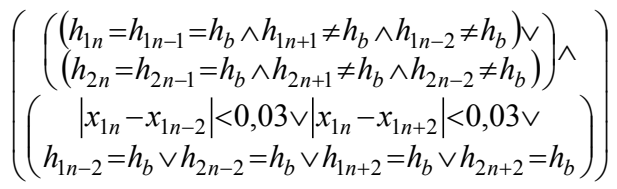

By using the dependence (6) it is possible to correct all types of wrong images, provided that between two incorrect frames there are at least two correct ones, i.e. the sequence: $\mathrm{G} \rightarrow \mathrm{G} \rightarrow \mathrm{B} \rightarrow \mathrm{B} \rightarrow \mathrm{G} \rightarrow \mathrm{G} \rightarrow \mathrm{B} \rightarrow \mathrm{B} \rightarrow \mathrm{G}$ $\rightarrow$ G. If the number of good frames is smaller, for example, in the sequence $\mathrm{G} \rightarrow \mathrm{G} \rightarrow \mathrm{B} \rightarrow \mathrm{B} \rightarrow \mathrm{G} \rightarrow \mathrm{B} \rightarrow$ $\mathrm{B} \rightarrow \mathrm{G}$, then correction will be possible for type I and II of wrong measurement images.

Where the number of incorrect frames appearing in a sequence is three, then correction is possible by using, firstly, Eq. (6), and afterwards Eq. (3), with limitations specific for these dependencies.

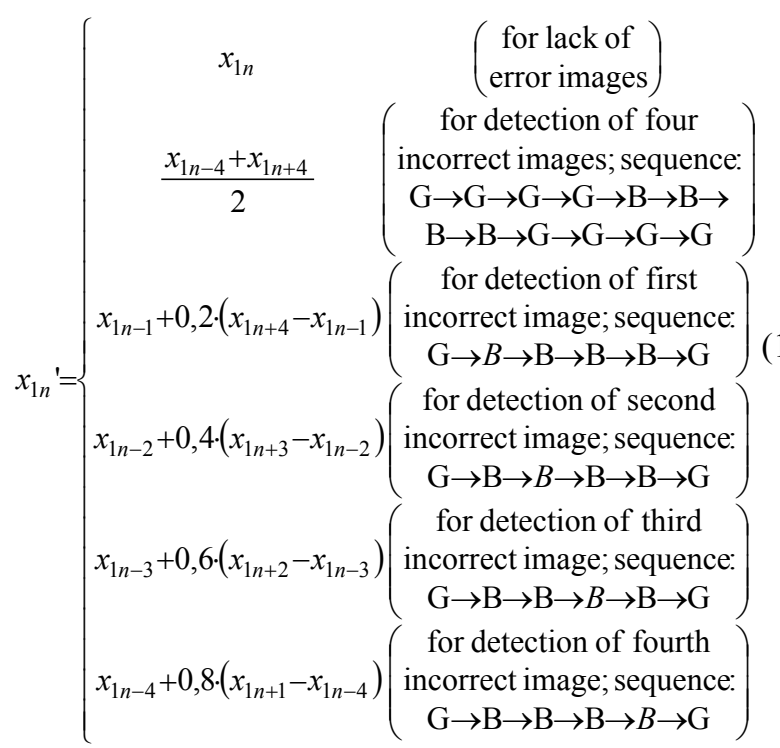

To correct four incorrect frames appearing in a sequence, it is necessary to use Eq. (11). As is the case with the smaller number of incorrect frames, correction is 
possible for all types of wrong images, when at least four frames appearing directly before and after the four wrong ones are correct. Otherwise, correction is possible only for type I and II of wrong measurement images.

The logical condition for detection of correct frames is presented in Eq. (12), and for detection of error frames, respectively for each type of sequences, in Eq. (13-17).

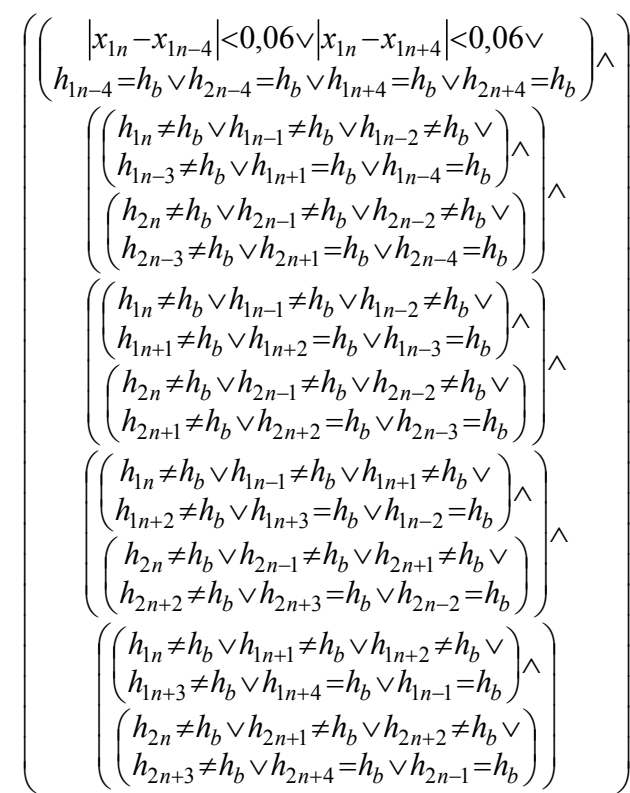$$
\left(\begin{array}{c}
\left|x_{1 n}-x_{1 n-4}\right|>0,06 \wedge\left|x_{1 n}-x_{1 n+4}\right|>0,06 \wedge \\
h_{1 n-4} \neq h_{b} \wedge h_{1 n+4} \neq h_{b} \wedge h_{2 n-4} \neq h_{b} \wedge h_{2 n+4} \neq h_{b}
\end{array}\right)
$$

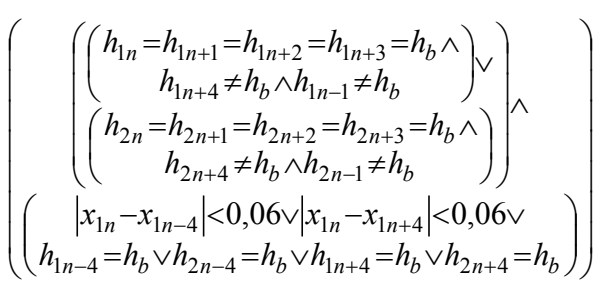

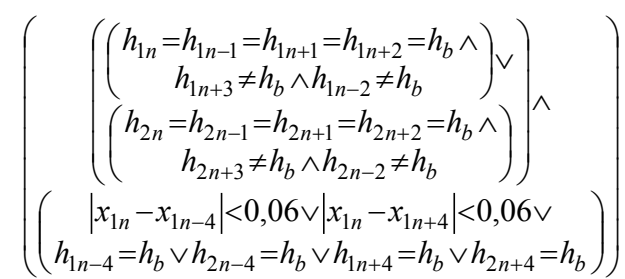

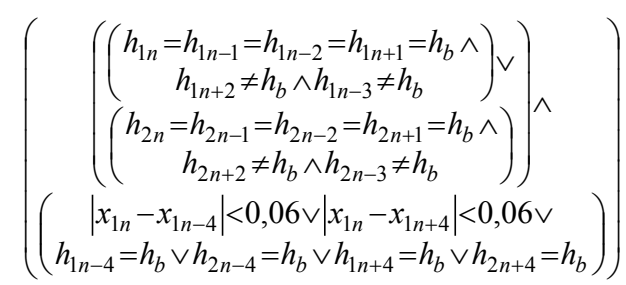

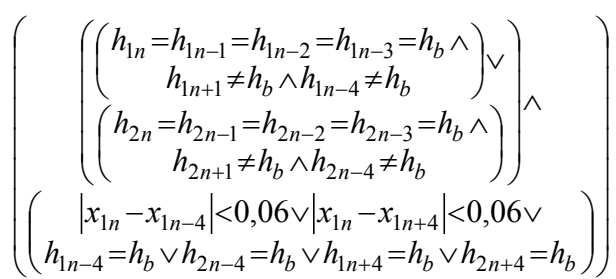

Starting from five incorrect measurement frames appearing in a sequence, the correction algorithm works only for type I and II of wrong measurement images. It has been ascertained that, with such strong disturbances in the measurement signal, these types of errors are dominant, and the other ones are practically non-existent. The mathematical dependence for this variant is presented below (18).

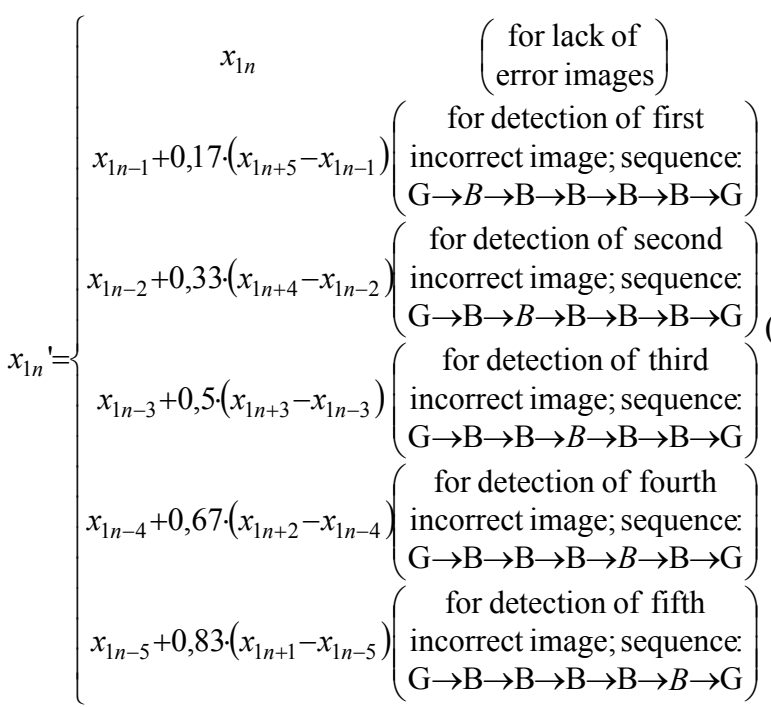

The logical condition for detection of correct frames is presented in Eq. (19), and for detection of error frames, respectively for each type of sequences, in Eq. (20-24).

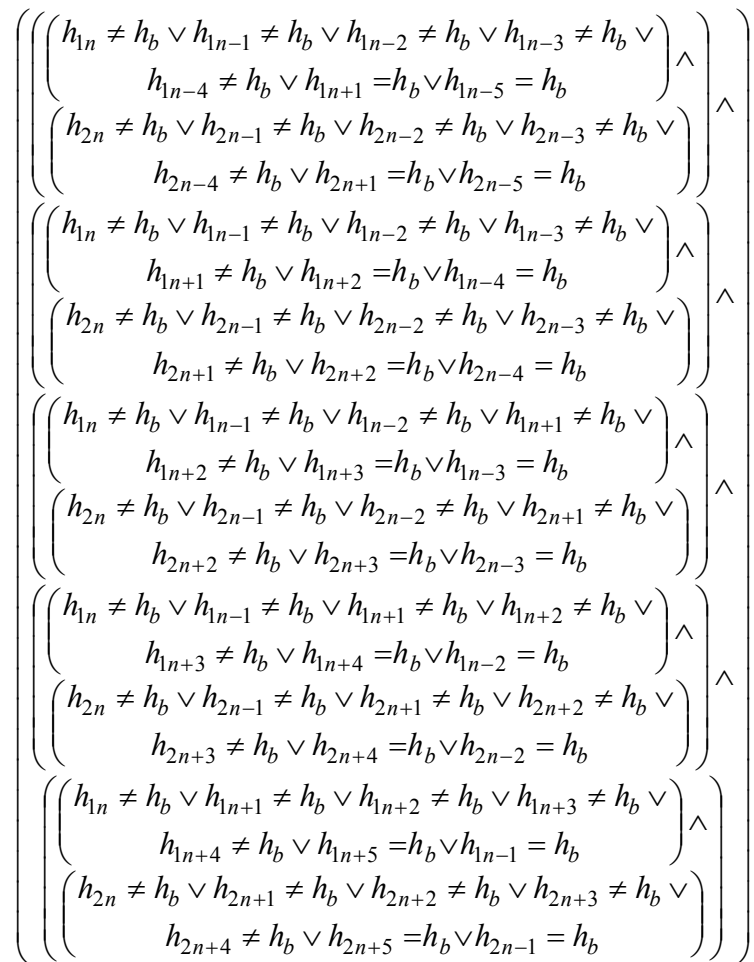

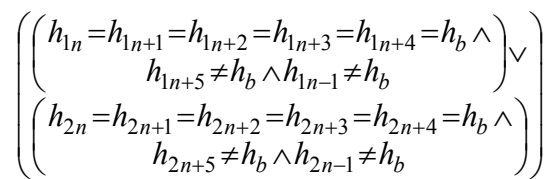




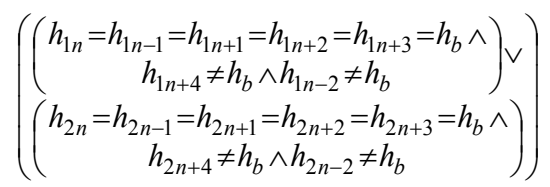

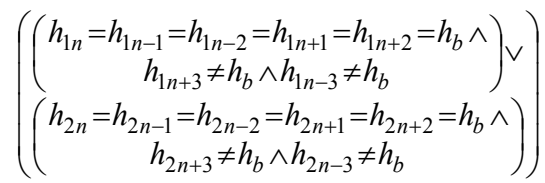

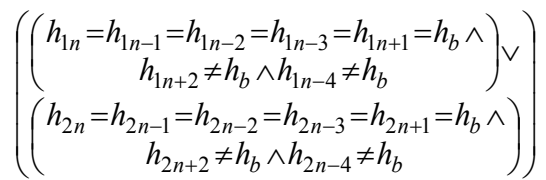

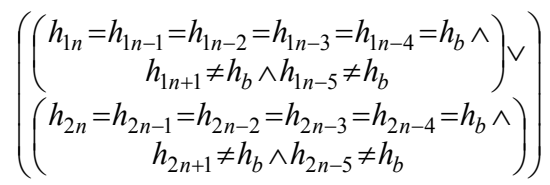

The dependencies for correction of more than five incorrect frames appearing in a sequence are analogous to Eq. (18). The maximum number of wrong frames appearing in a sequence is nine, as it has been decided that reliability of the measurement result is not acceptable with a greater percentage loss of the signal. The applied correction algorithm makes it possible, in theory, to correct measurement signal which contains only $10 \%$ of appropriately interpreted images. In practice, due to the randomness of incorrect image occurrence, it is possible to correct the measurement signal which contains about $35 \%$ of appropriately interpreted images.

\section{Implementation and validation}

The measurement procedure which is described above, has been implemented at a laboratory stand. For this purpose, the Basler camera type acA2040-180kc with frame grabber NI PCIe 1433, connected to a PC computer has been used. Digital image analysis and error correction algorithms were implemented in LabView software development environment. The sample results are presented and described below.

\subsection{Analogue filtration}

In order to present the process of analogue filtration in sample lighting parameters, two images were registered. One of them was registered without, and the other with a filter. Both images were registered with the same exposure parameters. The results of filter application are shown in Fig. 5.

a)

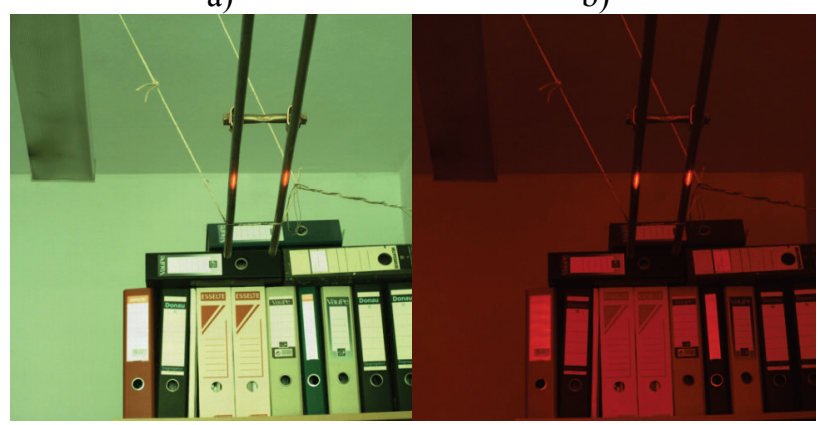

Figure 5 Optical filter in operation, where: a) picture before filtration; b) picture after filtration

Table 2 Results of image processing working for different lighting conditions

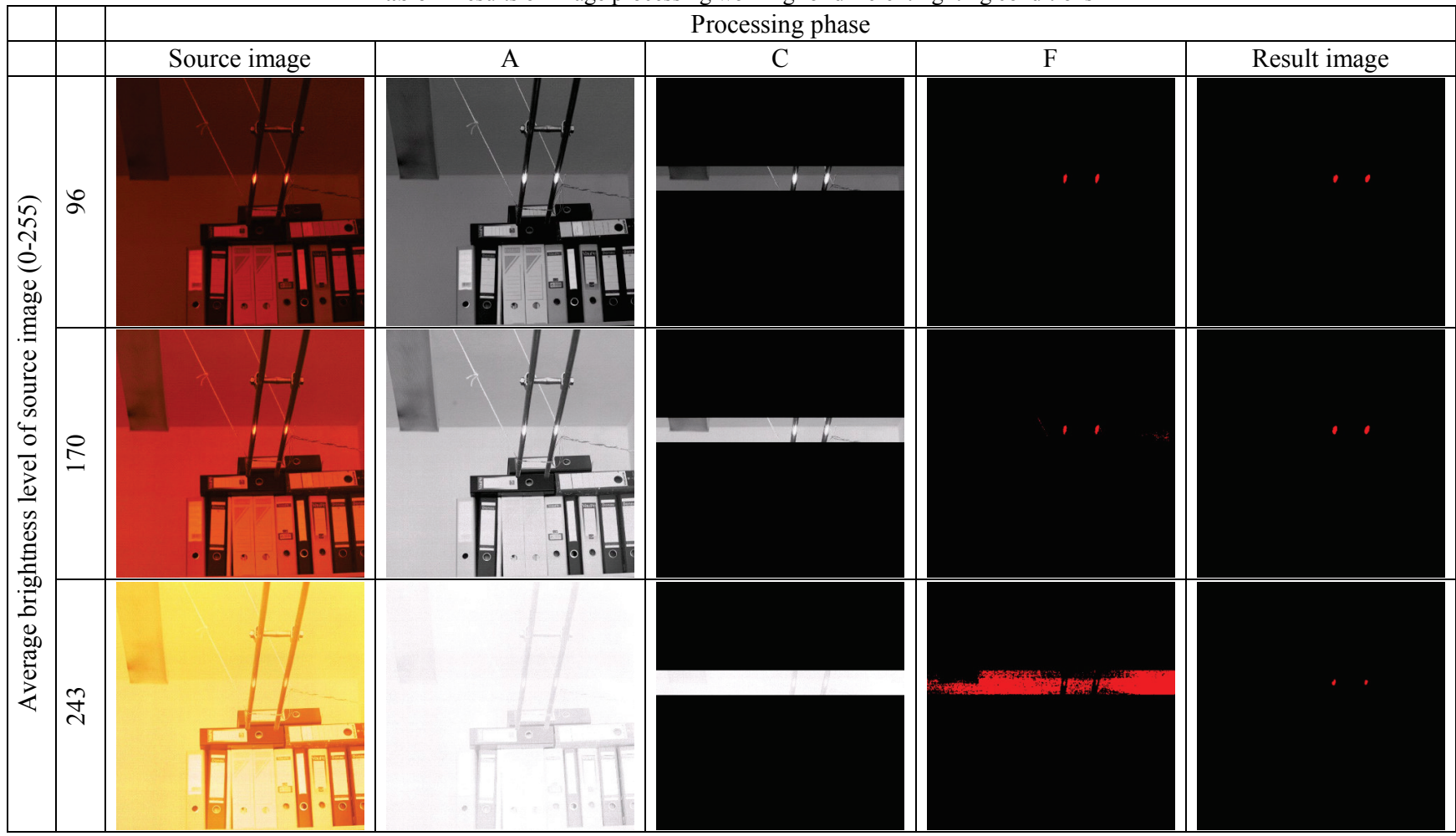




\subsection{Digital image analysis}

In order to check the algorithm of digital image processing in different ambient lighting conditions, sample images with significantly different average brightness level are recorded. The average brightness level of the image can theoretically change (with 8-bit sampling) from 0 (all image pixels are black) to the value of 255 (all image pixels are white). Results of the image analysis algorithm working for source images with different average brightness level are shown in Tab. 2 .

It can be observed that the applied algorithm makes it possible to obtain correct measurement results from the input image with extremely different parameters. Naturally, the darker the image, the easier it is to obtain a correct result. For a dark image the result is obtained after only four phases of processing. Bright images require more operations. It is important that, even if the correct result image is obtained during one of the earlier phases of the analysis, the subsequent transformations do not cause adverse changes of image.

\subsection{Error correction}

Verification of error correction algorithm was performed by using comparative method. A certain level of distortion was added to the reference signal (errorfree). Then this signal was subjected to the process of error correction. After the correction the obtained signal was compared to the reference signal. The level of differences between the signals is the measure of the quality of error correction process. Reference signals of stagger and suspension height of contact wires are presented in Fig. 6. Due to the fact that the results were obtained on a laboratory stationary stand, the displacements of contact wires were simulated by image camera movements.

a)

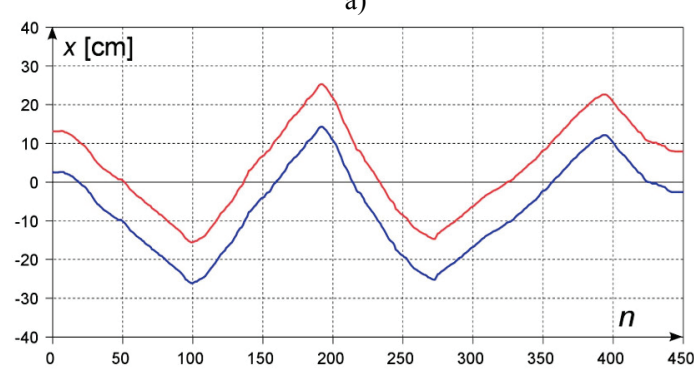

b)

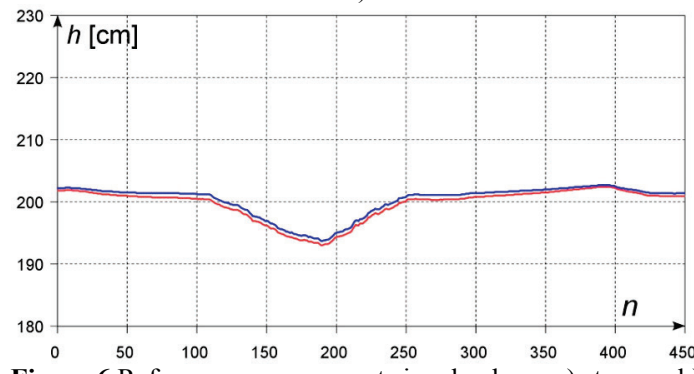

Figure 6 Reference measurement signal, where: a) stagger; b) suspension height ( $n$ - number of frames)

By adding some disturbances to the reference signal, the obtained signals contain respectively: 6,$3 ; 23 ; 53$ and $64 \%$ incorrect frames. The results of error correction process for the signal with $6,3 \%$ incorrect images are presented in Fig. 7.

a)

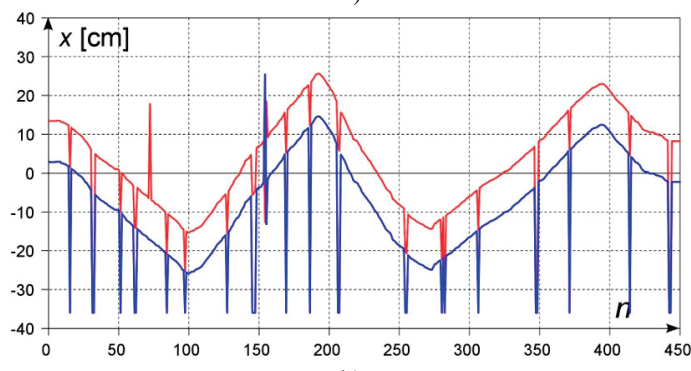

b)

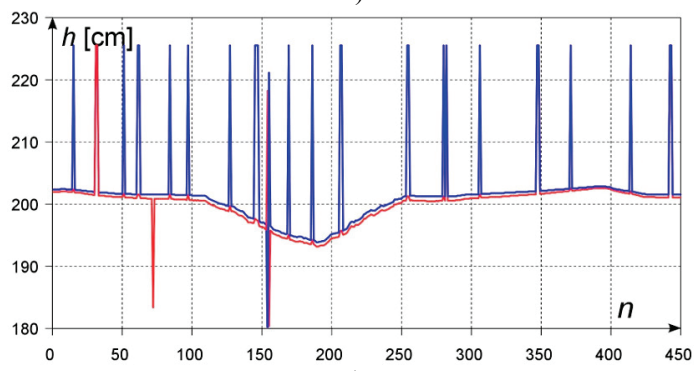

c)

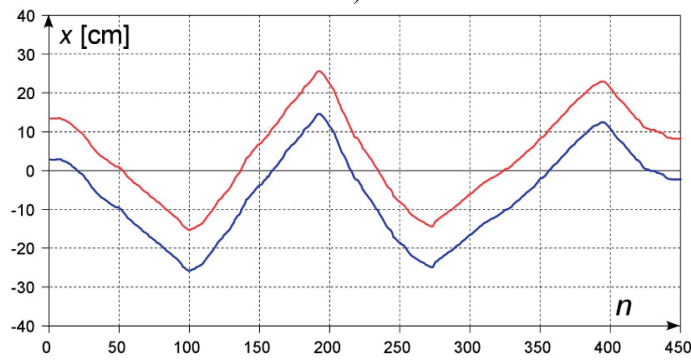

d)
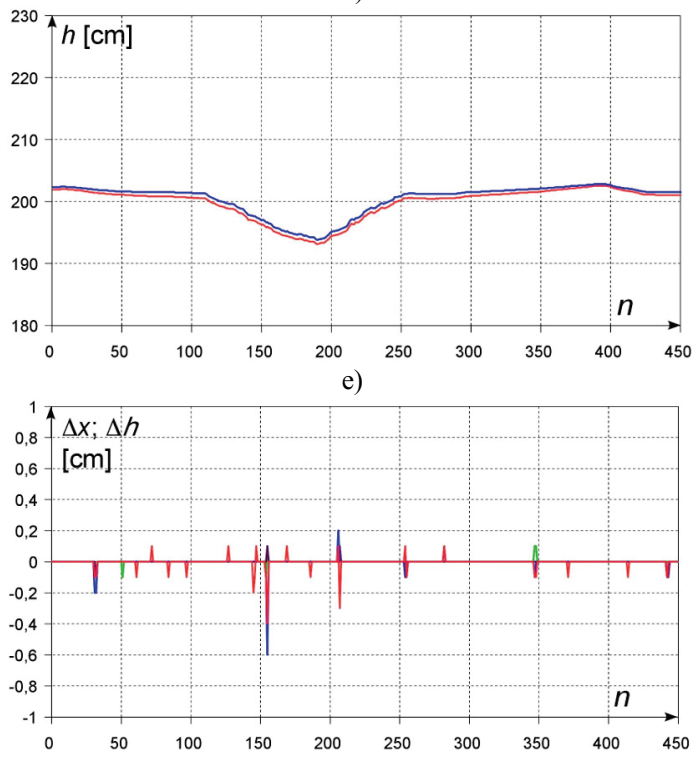

Figure 7 Work of error correction algorithm - signal with $6,3 \%$ of incorrect frames, where: a) stagger before correction; b) suspension height before correction; c) stagger after correction; d) suspension height after correction; e) differences between reference and corrected signal

As it can be seen, in places where correction is necessary, some differences between the reference and corrected signals appear. These differences do not exceed the value of $0,6 \mathrm{~cm}$, i.e. they are less than half the diameter of the contact wire.

Analogous results for the signal with $23 \%$ of losses are presented in Fig. 8. 
a)

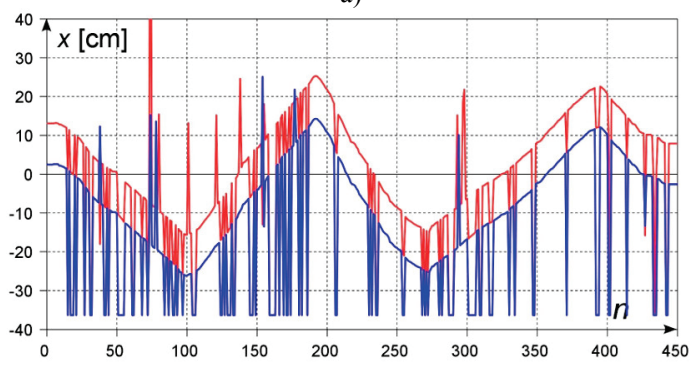

b)
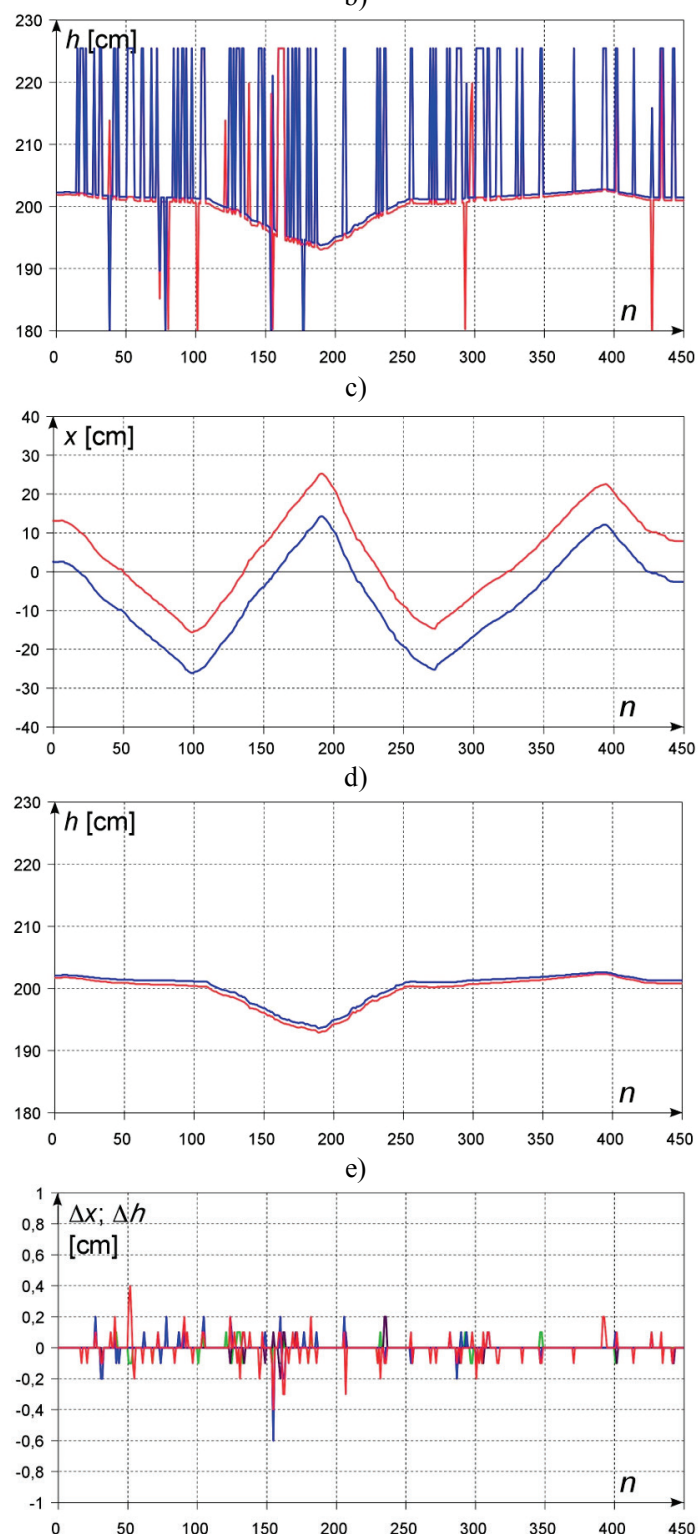

Figure 8 Work of error correction algorithm - signal with $23 \%$ of incorrect frames, where: a) stagger before correction; b) suspension height before correction; c) stagger after correction; d) suspension height after correction; e) differences between reference and corrected signal

The number of differences is bigger than in the previous case. However, their values are at the same level. In this case we can say that the increase of incorrect frame share to about $20 \%$ does not negatively influence the quality of the algorithm work.

The results for the signal with $53 \%$ of losses, are presented in Fig. 9.

In this case, the value of differences between the reference and corrected signal is similar to the previous cases, except for significant signal losses just before the two-hundredth frame. It is caused by the fact that this signal loss is in the position corresponding to the point of contact wire suspension. However, despite this, the error does not exceed the value of contact wire diameter.

a)

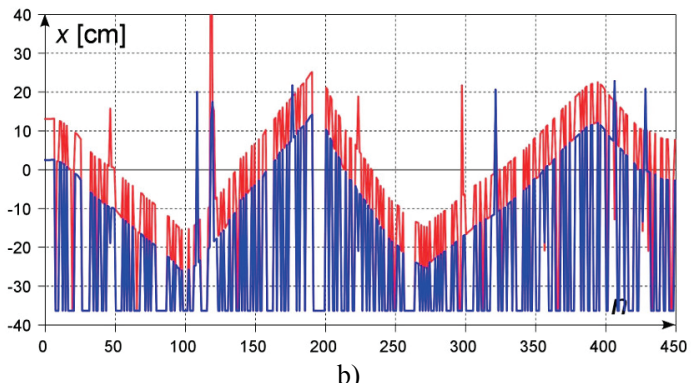

b)

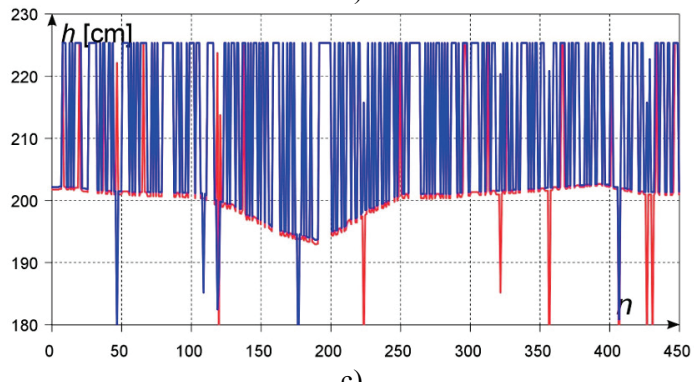

c)

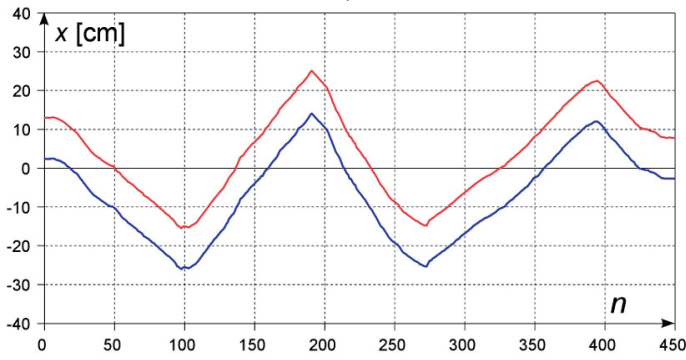

d)
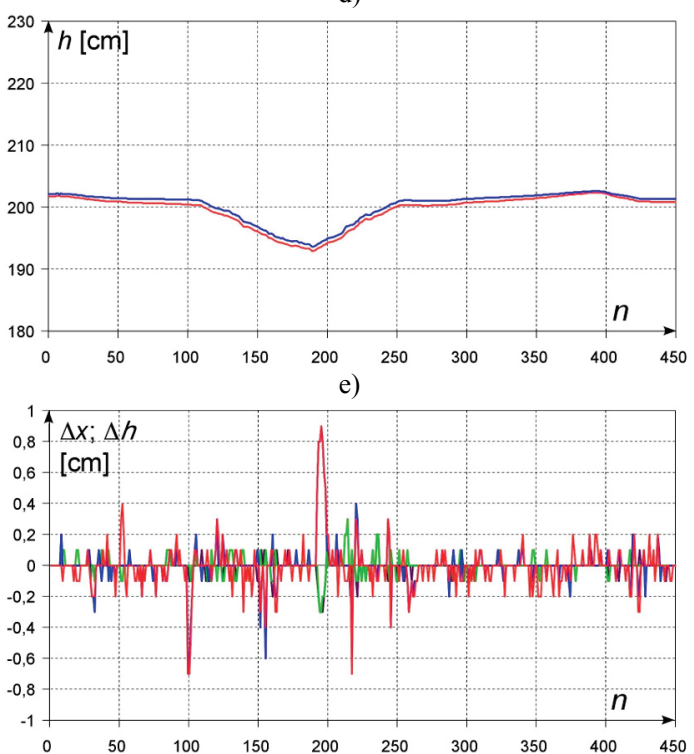

Figure 9 Work of error correction algorithm - signal with $53 \%$ of incorrect frames, where: a) stagger before correction; b) suspension height before correction; c) stagger after correction; d) suspension height after correction; e) differences between reference and corrected signal

The results for the signal with $64 \%$ losses are presented in Fig. 10. Experimental research shows that this is the upper level of measurement signal losses, which can be corrected by using the developed algorithm. 

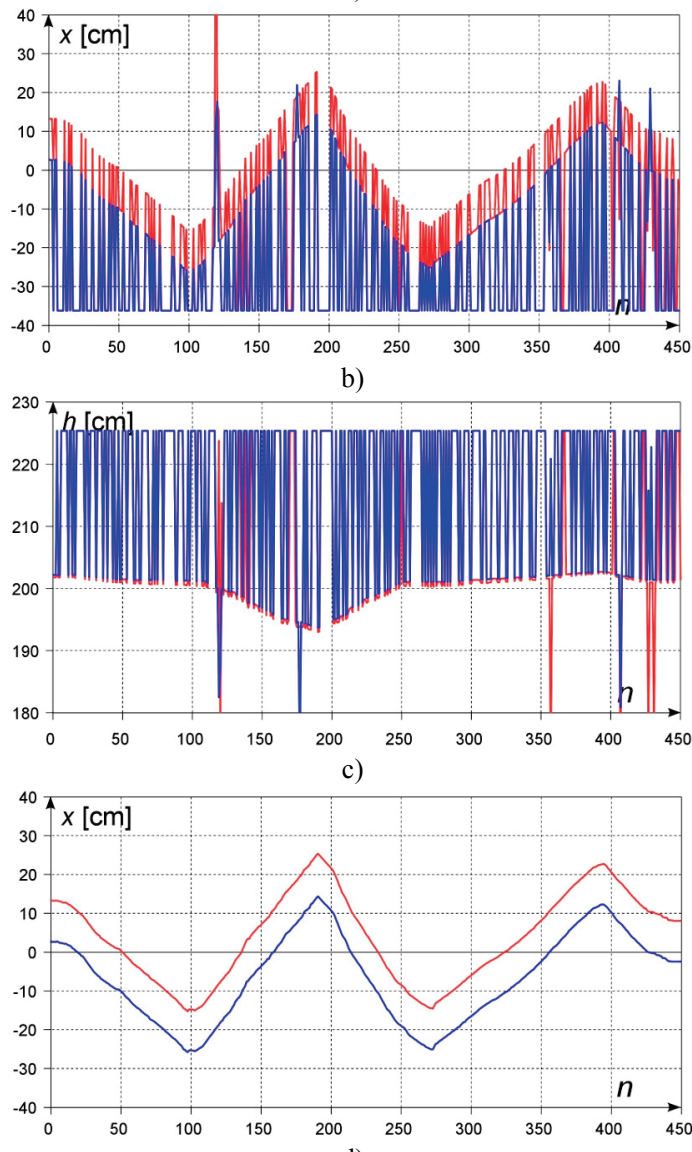

d)
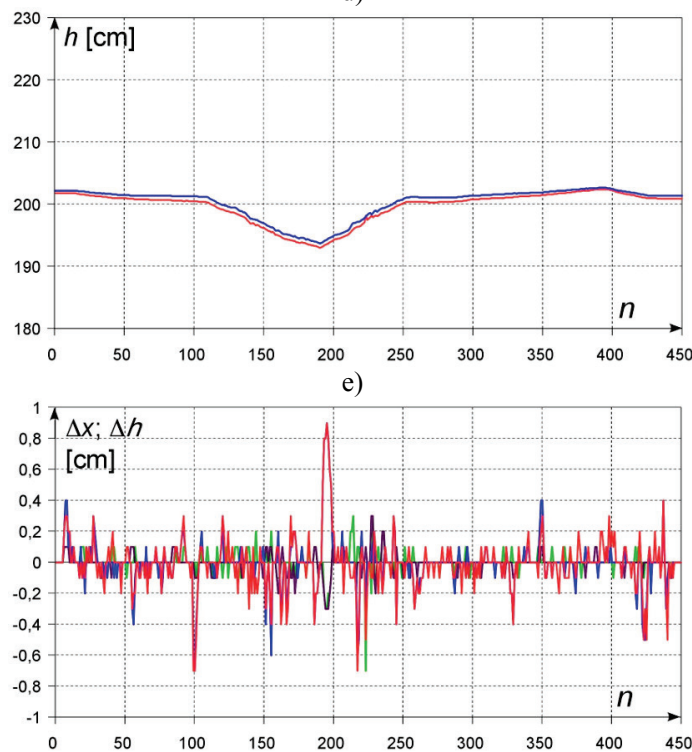

Figure 10 Work of error correction algorithm - signal with $64 \%$ of incorrect frames, where: a) stagger before correction; b) suspension height before correction; c) stagger after correction; d) suspension height after correction; e) differences between reference and corrected signal

Based on the conducted experimental research it can be said that the error correction algorithm works properly. The only thing which has to be improved is the work of the algorithm in the situation where signal losses occur within the area of the suspension point of contact wire.

\section{Conclusion}

The results show that the measurement system makes it possible to obtain correct measurement results of the contact wire position for various parameters of measurement image. The algorithm of image processing works properly even for source images whose brightness differs significantly. The system of error correction allows for elimination of high level of interference in the measurement signal. It must be noted that the presented system works properly during the measurement of a typical configuration of the catenary, i.e. for two contact wires. However, on the rail network, there are some places with untypical contact wires configuration, where there are more than two contact wires e.g. in network switches or on the catenary tension span. Further work will therefore be focused on correct interpretation of the image measured in unusual situations. The error correction system should also be adapted to these untypical contact wire configurations.

\section{References}

[1] Borromeo, S.; Aparicio, J. L. Automatic systems for wear measurement of contact wire in railways. // $28^{\text {th }}$ Annual Conference of the Industrial Electronics Society, IEEE / Sevilla, 2002, pp. 2700-2705. https://doi.org/10.1109/IECON.2002.1182821

[2] Kiessling, F.; Puschmann, R.; Schmieder, A.; Schneider, E. Contact lines for electric railways: planning, design, implementation, maintenance. Publicis Corporate Publishing, Erlangen, 2009.

[3] Fararooy, S.; Mair, C. Review of railway overhead wire geometry measurement systems. IEE Current Collections for High Speed Trains Seminar / Kingston Univ., 1998, pp. 4/1-4/4. https://doi.org/10.1049/ic:19981003

[4] Li, F.; Li, Z.; Li, Q.; Wang, D. Calibration of three CCD camera overhead contactline measuring system. // International Conference on Intelligent Computation Technology and Automation (ICICTA) / Changsha, 2010, pp. 911-913.

[5] Elia, M.; Diana, G.; Bocciolone, M.; Bruni, S.; Cheli, F.; Collina, A. Condition monitoring of the railway line and overhead equipment through onboard train measurement an Italian experience. // The Institution of Engineering and Technology International Conference on Railway Condition Monitoring / Birmingham, 2006, pp. 102-107.

[6] Moretti, M.; Triglia, M.; Maffei, G. Archimede - the first European diagnostic train for global monitoring of railway infrastructure. // IEEE Intelligent Vehicles Symposium / Parma, 2004, pp. 522-526. https://doi.org/10.1109/IVS.2004.1336438

[7] Hayasaka, T.; Shimizu, M.; Nezu, K. Development of contact-loss measuring system using ultraviolet ray detection. // RTRI. 50, 3(2009), pp. 131-136. https://doi.org/10.2219/rtriqr.50.131

[8] Hofler, H.; Dambacher, M.; Dimopoulos, N.; Jetter, V. Monitoring and inspecting overhead wires and supporting structures. // IEEE Intelligent Vehicles Symposium / Parma, 2004, pp. 512-517.

[9] Kusumi, S.; Nezu, K.; Nagasawa, H. Overhead contact line inspection system by rail-and-road car. // RTRI. 41, 4(2000), pp. 169-172. https://doi.org/10.2219/rtriqr.41.169

[10] Bruno, O.; Landi, A.; Papi, M.; Sani, L. Phototube sensor for monitoring the quality of current collection on overhead electrified railways. // Journal of Rail Rapid Transit, May (2001), pp. 231-241.

[11] Aydin, I.; Karaköse, M.; Akin, E. A New contactless fault diagnosis approach for pantograph-catenary system. // 15th International Symposium MECHATRONIKA, IEEE / Prague, 2012, pp. 1-6. 
[12] Shing, A. W. C.; Pascoschi, G. Contact wire wear measurement and data management. // The Institution of Engineering and Technology International Conference on Railway Condition Monitoring / Birmingham, 2006, pp. 182-187.

[13] Usuda, T. Estimation of wear and strain of contact wire using contact force of pantograph. // RTRI. 48, 3(2007), pp. 170-175. https://doi.org/10.2219/rtriqr.48.170

[14] Tsunemoto, M.; Harada, S.; Shimizu, M. Features of contact wire wear and measures for local wear on simple catenary with copper-steel contact wire. // RTRI. 48, 2(2007), pp. 83-88. https://doi.org/10.2219/rtriqr.48.83

[15] Skibicki, J. The new version of contact-less method for localisation of catenary contact wire - theoretical assumption. // Przegląd Elektrotechniczny. 7(2013), pp. 100-104.

[16] Skibicki, J. Analiza wymagań sprzętowych dla bezkontaktowego system pomiaru położenia przewodu jezdnego sieci trakcyjnej do celów diagnostycznych. // Logistyka. 6(2014), pp. 9599-9606.

[17] Relf, C. G. Image acquisition and processing with LabVIEW. CRC Press, Boca Raton London New York Washington, 2004.

\section{Authors' address}

Jacek Skibicki, Assistant Prof. Ph.D.

Gdansk University of Technology

Faculty of Electrical and Control Engineering

Department of Electrical Engineering in Transport

ul. G. Narutowicza 11/12

80-233, Gdańsk, Poland

E-mail: jacek.skibicki@pg.gda.pl 